\title{
Ground Penetrating Radar as a Tool for the Diagnostics of Concrete Pavements
}

\author{
J. Stryk* \& R. Matula \\ Department of Infrastructure and Environment, CDV - Transport Research Centre, Brno, Czech Republic \\ *Corresponding author: josef.stryk@cdv.cz
}

\begin{abstract}
This paper describes the basic possibilities for the usage of ground penetrating radar (GPR) in road diagnostics. The opportunity for multi-channel GPR use and the limitations arising from measurements performed at high speeds are described. Particular attention is paid to the problems of the diagnostics of concrete pavements. The radar configuration used for location of dowel bars and tie bars is presented.
\end{abstract}

KEY WORDS: Ground penetrating radar, GPR, diagnostics, pavement, guidelines.

\section{GROUND PENETRATING RADAR}

GPR is a piece of equipment which uses high frequency electromagnetic waves. In combination with suitable software it provides the location and an evaluation of the electrical and magnetic features of the studied environment in which these waves radiate.

The boom in GPR usage started with the commercial selling of this equipment by the American company GSSI in 1972. GPR started to be used in a lot of different areas of human activity. One of these areas is in the diagnostics of roads and bridges, which is a common event nowadays (Fauchard et al. 2000), (Al-Qadi et al. 2003), (Forest et al. 2004).

\section{ROAD DIAGNOSTICS}

Horn antennas which are placed 300 - $500 \mathrm{~mm}$ above the pavement surface (for continual measurements) are commonly used in Europe and in the USA. Dipole antennas are commonly used in the United Kingdom. The best results are obtained if a dipole antenna is placed directly on the pavement surface (for continual measurements it is placed approximately $30 \mathrm{~mm}$ above the pavement surface).

The measurement is carried out locally or continuously. In the case of a continual survey the GPR system is fixed to a special cart or to a measuring car. The survey is carried out at a slow speed (from walking pace up to $25 \mathrm{~km} / \mathrm{h}$ - mostly dipole antennas) or at a high speed ( $80 \mathrm{~km} / \mathrm{h}$ and more - mostly horn antennas). The main advantage of the high speed survey is the fact that you do not need to close a measured road or to limit traffic on the measured section.

One of the first applications of GPR in the field of road diagnostics was for the location of dowel bars/ tie bars in concrete pavements (Utsi \& Utsi, 2004) and the determination of pavement layer thicknesses (Al-Qadi et al. 2005). Currently a GPR application in those 
areas is used ordinarily because research in this area is so advanced that it enables the interpretation of measured data to a very high standard. GPRs using antennas with frequency ranges in $\mathrm{GHz}$, controllers capable to operate more channels simultaneously, 3D evaluating software, etc., are able to guarantee sufficiently quick data collection and their following evaluation (Fan-nian, 2000).

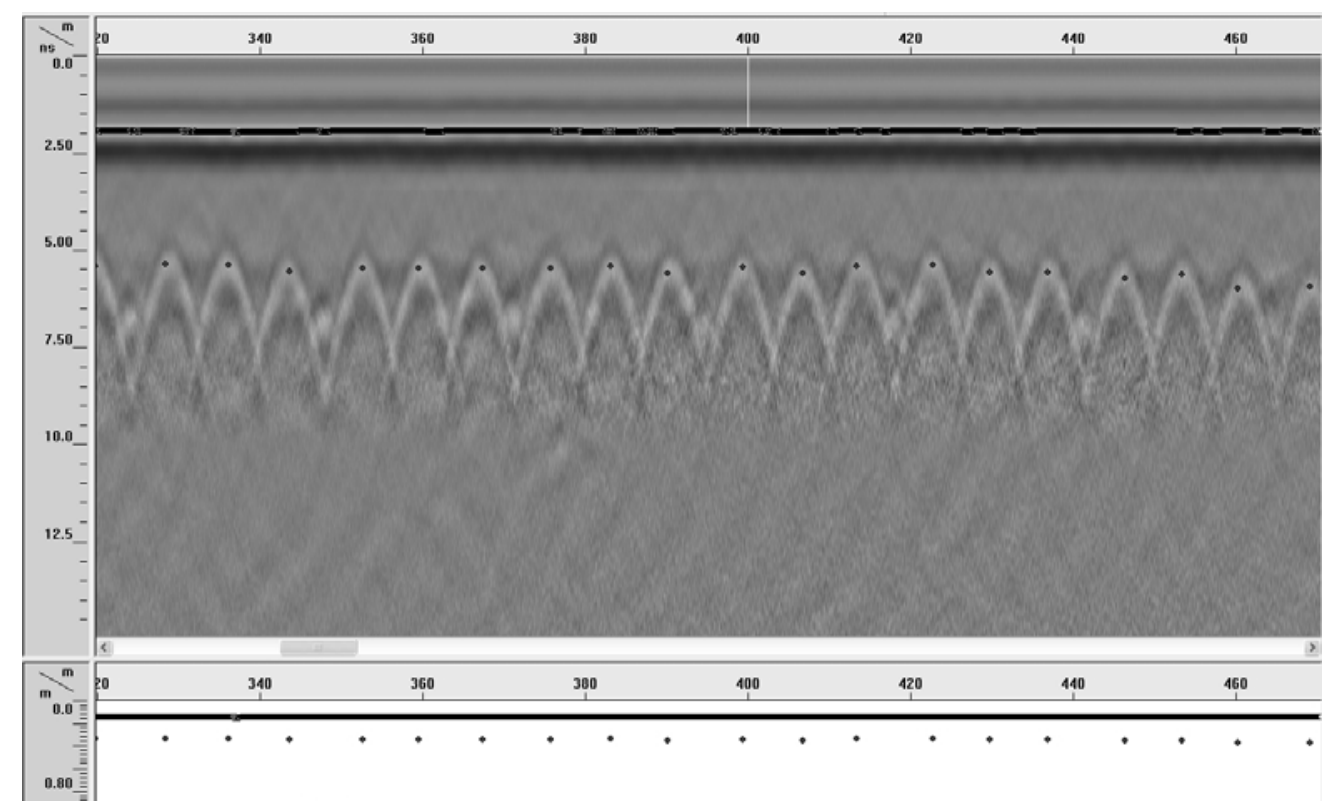

Figure 1: An example of a radargram - location of tie bars in concrete pavement.

Figure 1 presents a radargram from a GPR survey using a $1.0 \mathrm{GHz}$ antenna focused on the location of tie bars in a longitudinal joint of a concrete pavement. This record is further evaluated for determining displacement of tie bars from the center (ideal) location.

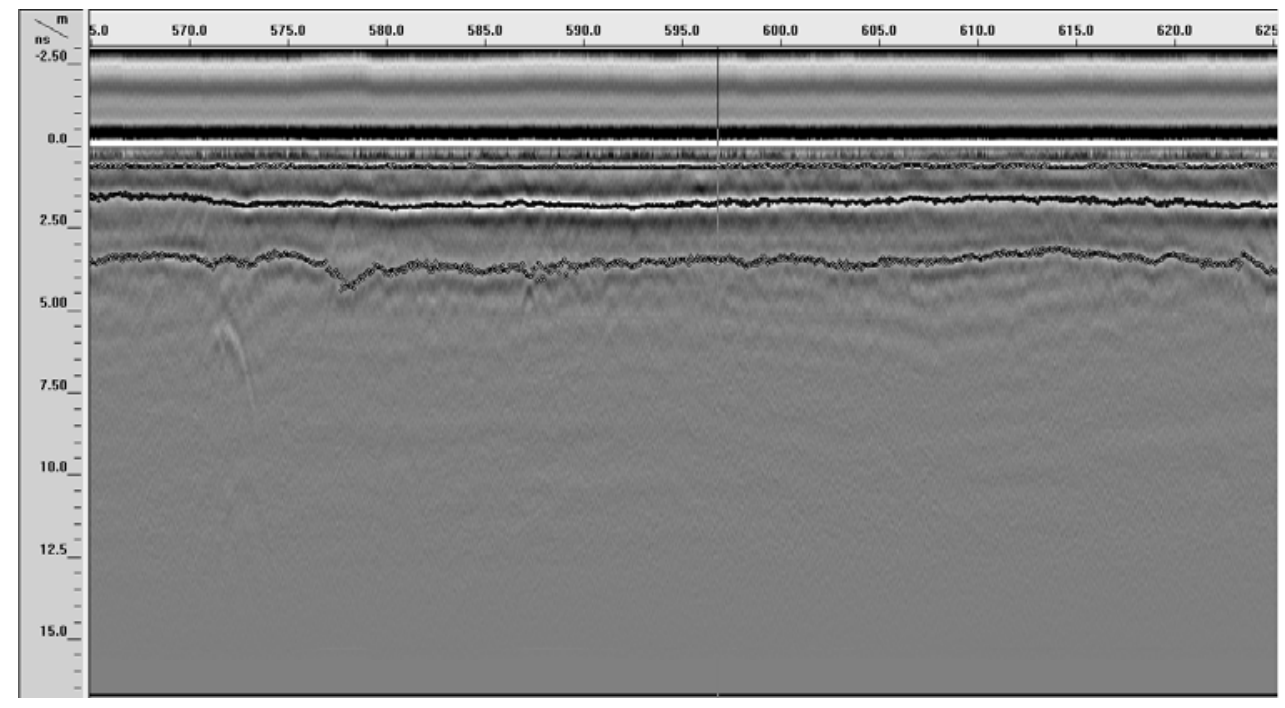

Figure 2: An example of a radargram - the determination of the layer thicknesses of a pavement with asphalt courses

Figure 2 presents a radargram from a GPR survey focused on the determination of construction layers thicknesses of a newly constructed flexible pavement. Surface course, binder course, and base course are marked in colour in the record. 
The other contribution to the development of GPR systems was the usage of the antennas' array. On the basis of its usage it is possible to carry out an auto calibration of layer depth measurements. The main advantage is a minimization of the needed cores along the investigated area (Green, 2006).

During the high speed measurement it is possible to locate bigger defects. The smaller defects can be detected but you have to use a lower measurement speed. The main disadvantage of slow speed measurements is a limitation of traffic and the need for road closures.

\section{MEASURING DEVICES IN CDV}

CDV uses an American system GSSI for GPR measurements in the following two versions:

- The configuration RoadScan $1.0 \mathrm{GHz}$ mounted on a Volkswagen van for measurements at speeds up to $80 \mathrm{~km} / \mathrm{h}$ (evaluation unit SIR-20, horn antenna $1.0 \mathrm{GHz}$, supporting frame with treads for calibration, distance indicator located on a back wheel of the vehicle and a calibration plate), see Figure 3.

- A cart for measuring the location of dowel bars and anchors produced and completed at the TRC (the cart, assessment unit SIR-20, two antennas $1.6 \mathrm{GHz}$ of a dipole type, a distance indicator mounted on a separate wheel and a power supply), see Figure 4.

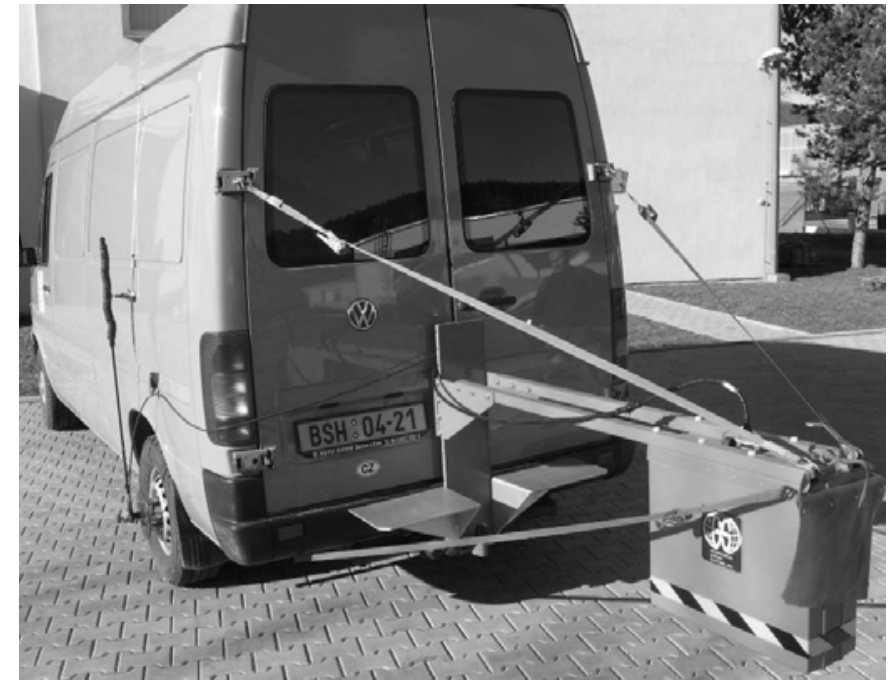

Figure 3: Configuration RoadScan 1.0 GHz mounted on a measuring vehicle.

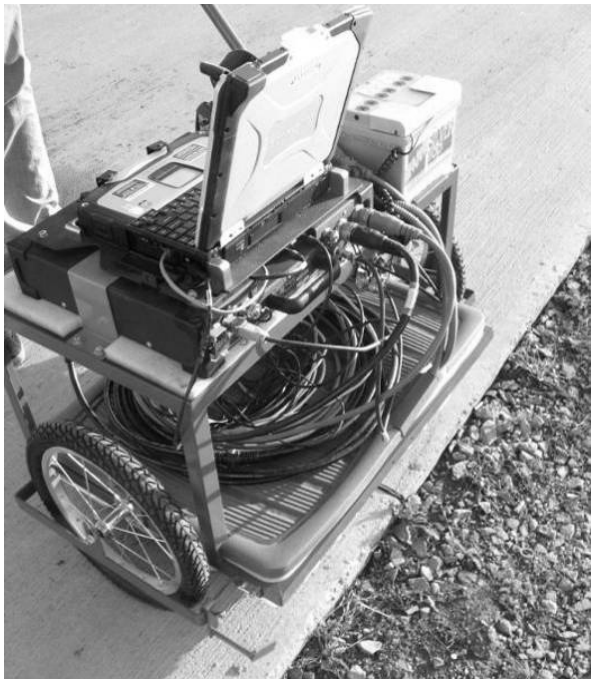

Figure 4: CDV cart with two antennas 1.6 GHz.

\section{PREPARATION FOR THE DIAGNOSTICS OF CONCRETE PAVEMENTS USING GPR}

The main principle of this preparation was to detect and correctly localize the location of reinforcement. In the standard ČSN 73 6123-1 Road building - Concrete pavements - Part 1: Construction and conformity assessment the following maximum allowed differences between actual location of dowel bars and location designed at the documentation are defined:

a) $20 \mathrm{~mm}$ towards the upper slab surface (in the vertical direction),

b) $20 \mathrm{~mm}$ towards the longitudinal axis of the concrete pavement (in the horizontal direction),

c) $50 \mathrm{~mm}$ towards a transverse joint of a cement concrete surface course (shift in longitudinal direction). 
The aim of the experiment was to determine the accuracy we are able to determine the location of dowel bars in a concrete pavement.

A concrete slab with 3 inbuilt dowel bars was produced. The first dowel bar (A) was placed at an ideal location without any shift in either horizontal or vertical direction. The second dowel bar was shifted within the frame of tolerable limits set in ČSN 73 6123-1 and the last dowel bar was located outside the range of these limits.

First, a calibration of the manual cart for distance measurements and GPR calibration by a metal plate located on the surface of the slab was made. Seven crossing measurements of the slab in the direction perpendicular to the location of dowel bars were performed at various distances. During the measurements the perpendicular distances from the antenna to the slab edge were read in two directions, $\mathrm{x}$ and $\mathrm{y}$, at the beginning and at the end of the measurement. Performed measurements were evaluated in the program RADAN. The determined location of dowel bars using a GPR was compared with their actual location (see Figure 5).

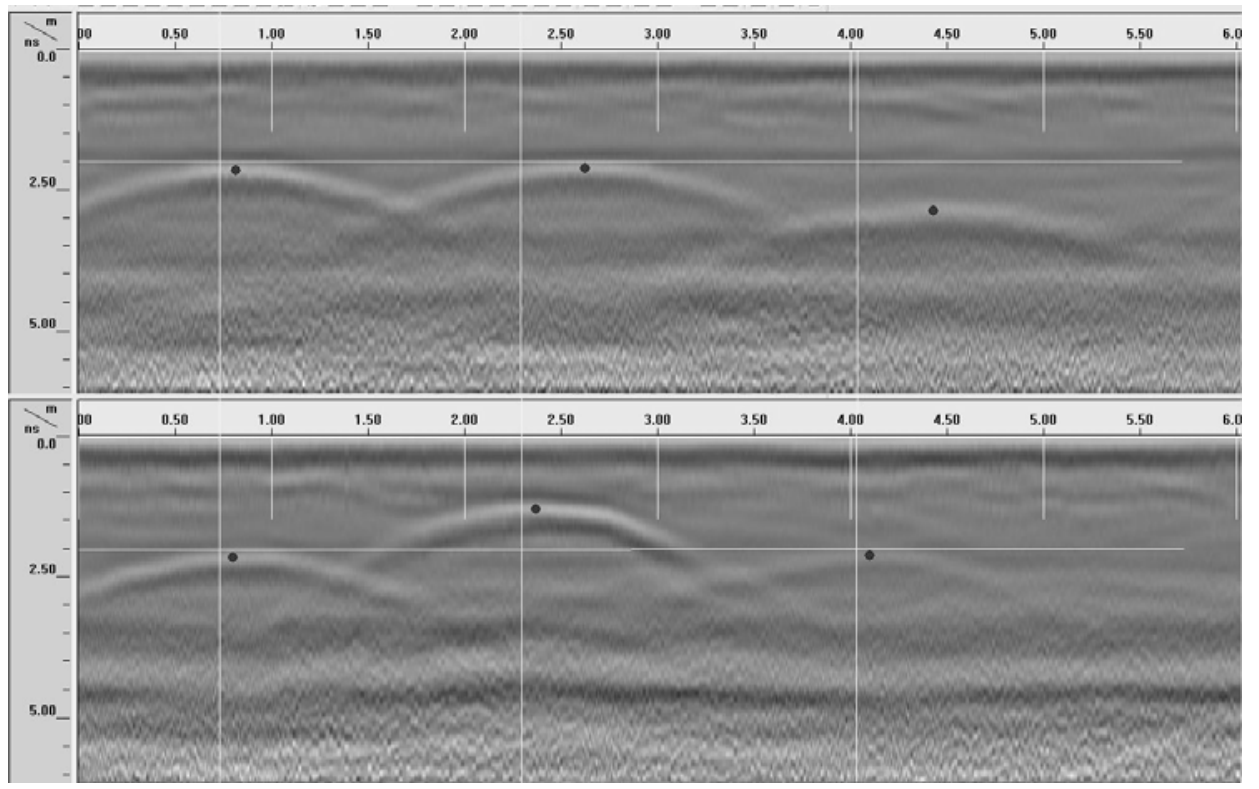

Figure 5: Evaluation of the location of dowel bars in a concrete slab using the program RADAN, comparison of two crossings with a distance $400 \mathrm{~mm}$ with visible differences (the dowel bar location is always on the top of displayed parabola).

On the basis of the results of this experiment we concluded that, first, it is necessary to pay attention to the correct location of the antenna at the measurement in order to maintain the accuracy of the measurement in the horizontal direction $+/-5 \mathrm{~mm}$. In the vertical direction the measurement was performed with average accuracy $+/-3 \mathrm{~mm}$. Here we must be reminded that this accuracy was attained using the fact that the thickness of the slab was known and constant all over the slab area. Further, it showed that at the measurements carried out near the ends of the bars are less readable (the parabola is less visible and the accuracy of the measurement is lower).

\section{LOCATION OF DOWEL BARS AND TIE BARS}

After laboratory tests in situ measurements were performed. For the purpose of measuring the reinforcement of the longitudinal and transversal joints of the concrete pavement a section on the motorway D1 was chosen. 
In the transversal direction measurements across the whole profile of the motorway were performed. In the longitudinal direction the measurements were performed on 70 meters of the length. The axial distance of two $1.6 \mathrm{GHz}$ antennas was set to $300 \mathrm{~mm}$. By parallel use of two antennas of the same type and frequency higher accuracy for determining dowel bars displacement was assured rather than if only one antenna had been used and measurement had been performed twice, once at the left side of the joint, and once at the right side of the joint.

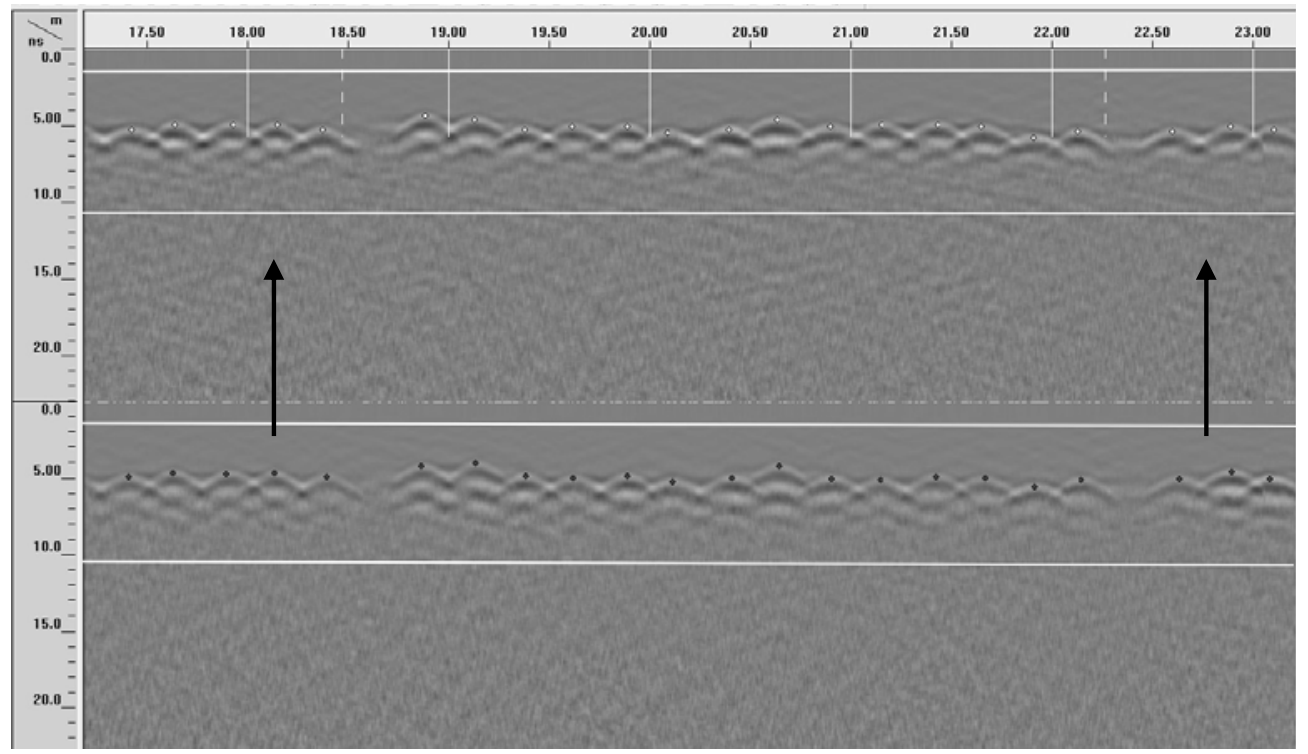

Figure 6: An example of a radargram - location and displacement of dowel bars.

Figure 6 presents an example of the evaluation of the location of dowel bars in the program RADAN. The length of the record is 6 meters. The radargram is divided into two parts which demonstrate data records from two channels, each of which represents a measurement on another side of a transversal joint. The location of dowel bars is represented by the tops of parabolas marked with a point; white lines represent the surface and the bottom of the slab, and a boundary between particular slabs is marked by an arrow.

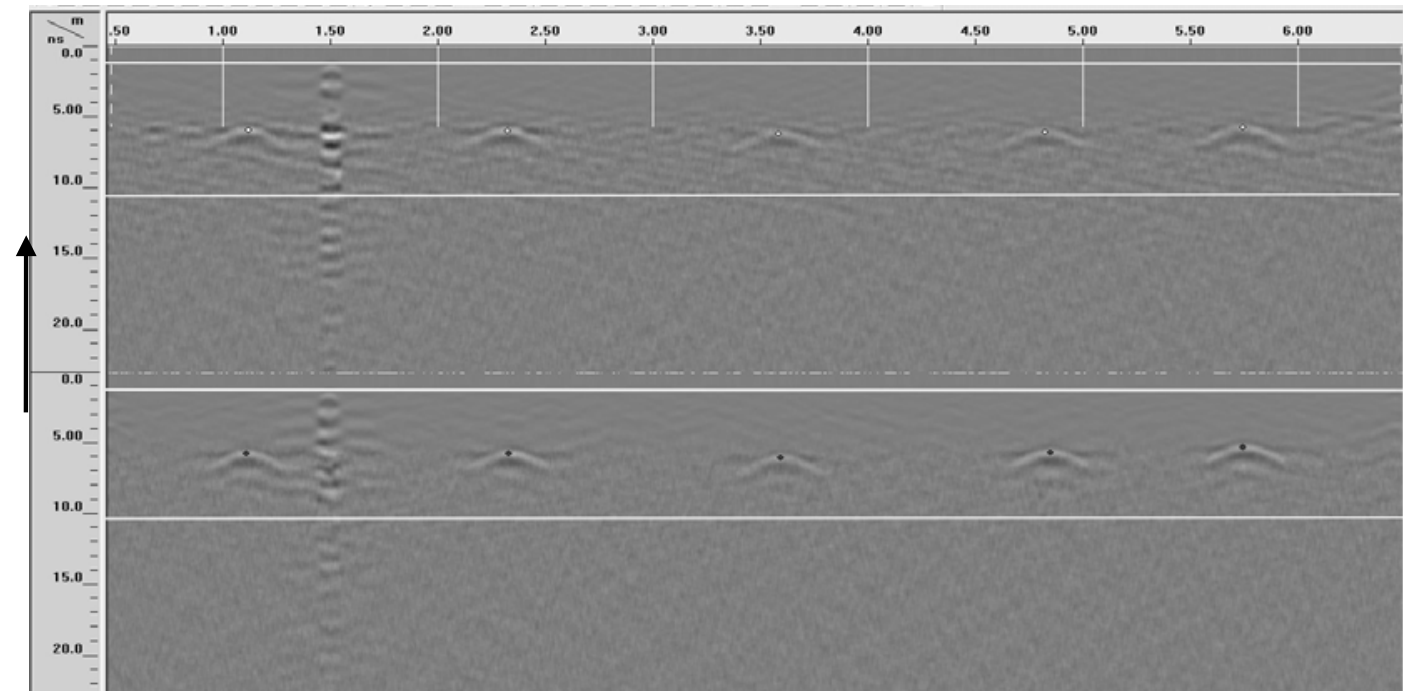

Figure 7: An example of a radargram - location and displacement of tie bars.

Figure 7 presents an example of the evaluation of the location of tie bars in the program RADAN. The record length is also 6 meters long. The interruption of the radargram 
at the location 1.5 meter corresponds to the calibration plate which was placed on the pavement surface.

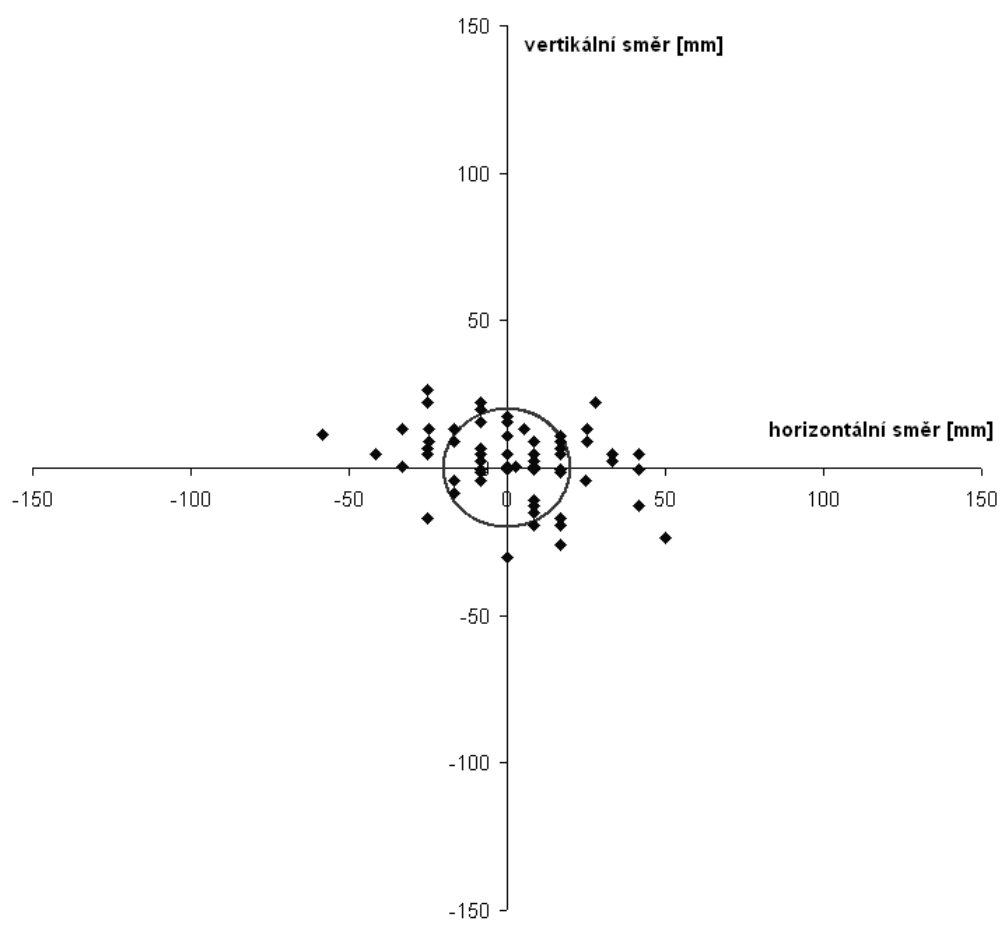

Figure 8: Locations of ends of dowel bars towards the center (ideal) location and their horizontal and vertical displacement.

Figure 8 summarises the location of the ends of measured dowel bars towards the center (ideal) location and their horizontal and vertical displacement in a concrete pavement of $300 \mathrm{~mm}$ thickness. The circle marks the boundary location of the ends of dowel bars according to the ČSN 73 6123-1.

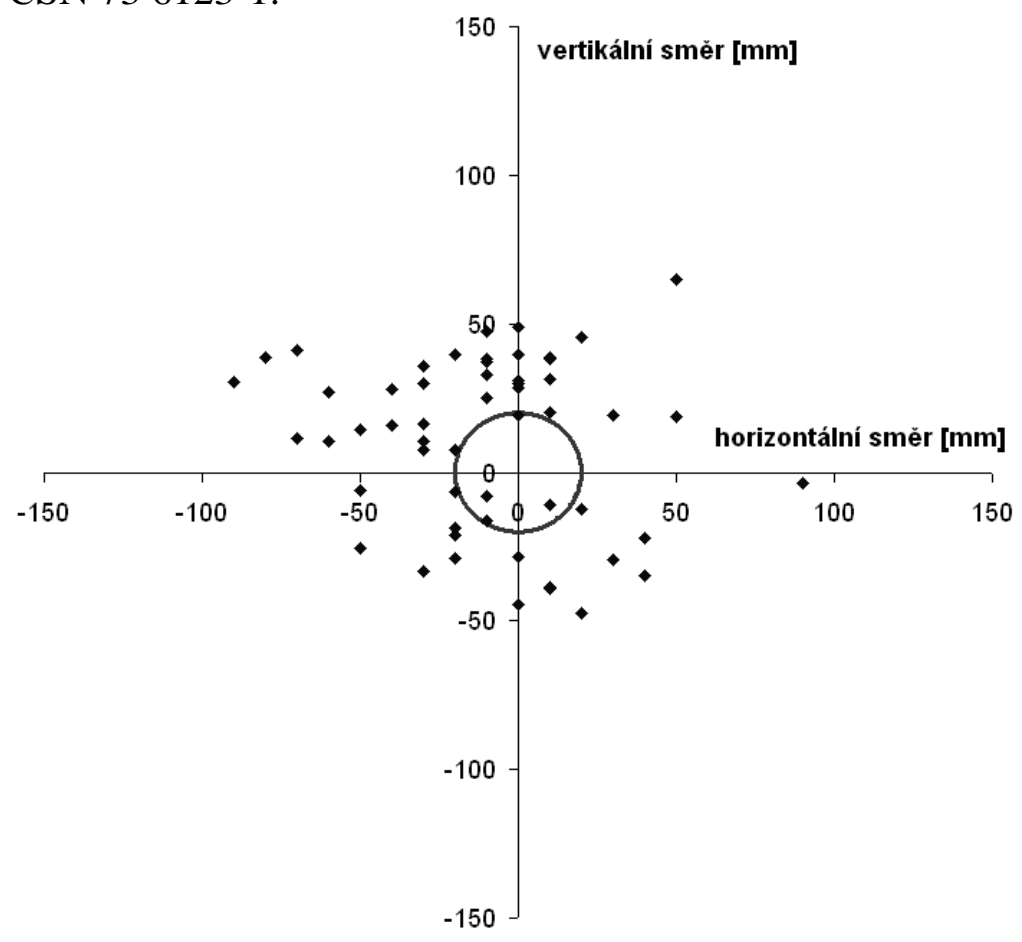

Figure 9: Locations of the ends of tie bars towards the center (ideal) location and their horizontal and vertical displacement. 
Figure 9 presents the location of the ends of tie bars towards the center (ideal) location and their horizontal and vertical displacement in a concrete pavement of $300 \mathrm{~mm}$ thickness. The circle marks the boundary location of the ends of tie bars according to the ČSN73 6123-1.

It is apparent that even if the boundary location is widened by the measurement accuracy some dowel bars and quite a lot of tie bars will be standing outside the defined limits on the surveyed sections.

Other information concerning GPR testing in general and NDT testing carried out in CDV can be found in (Stryk \& Pospíšil, 2006), (Stryk, 2007), (Kořenská, Pazdera et al. 2005) and (Štulířová \& Pospíšil, 2008).

\section{CONCLUSIONS}

The high accuracy of the measurements of the location of dowel bars and tie bars in the horizontal and vertical directions were attained during laboratory measurements.

During in situ measurements the accuracy is decreased because of varied causes, e.g., the change of concrete quality on various sections which can influence the speed of electromagnetic signal propagation in this environment. It is therefore necessary to monitor the slab thickness in order to exclude the influence of these changes in the case of recording an extreme displacement of location of dowel bars and tie bars. It is optimal to determine the thickness of a concrete pavement by one or more cores.

Another influence is the speed of the measurement and the corresponding settings of sampling. It is optimal to perform measurements with a CDV cart at a walking speed. Use of the cart with two antennas enables one to assess the displacement of the dowel bars and tie bars in horizontal and vertical directions.

\section{REFERENCES}

Al-Qadi I. L., Lahouar S., Loulizi A.: Successful Application of GPR for Quality Assurance/Quality Control of New Pavements. In: $82^{\text {th }}$ Annual Meeting of Transportation Research Board, January 12-16, 2003, Washington, D.C., CD-ROM.

Al-Qadi I. L., Lahouar S., Jiang K., MeGhee K. K., Mokarem D.: Validation of Ground Penetration Radar Accuracy for Estimating Pavement Layer Thicknesses. In: $84^{\text {th }}$ Annual Meeting of Transportation Research Board, January 9-13, 2005, Washington, D.C.,CDROM.

ČSN 73 6123-1 Stavba vozovek - Cementobetonové kryty - Č́st 1: Provádění a kontrola shody (Road building - Concrete pavements - Part 1: Construction and conformity assessment), 2006

Fan-nian Kong.: Choice of Antenna Type and Frequency Range for Testing of Concrete Structures. In: $8^{\text {th }}$ International Conference on Ground Penetrating Radar, 22-26 May, 2000, Gold Coast, Australia, CD-ROM.

Fauchard C., Dérobert X., Côte Ph. GPR Performances on Road Test Site. In: $8^{\text {th }}$ International Conference on Ground Penetrating Radar, 22-26 May, 2000, Gold Coast, Australia, CD-ROM. 
Forest R., Pynn J., Alani A., Ferne B. The Use of Ground Penetrating Radar for the Monitoring of Road Properties. In: TRL annual research review 2003. Crowthorne: TRL, 2004, pp. 25-37.

Green R., Lund A., Birken R.: Generation of Utility Mapping Data via Processing of MultiChannel Signals Collected by Arrays of GPR and EM Antennae. In: 85 ${ }^{\text {th }}$ Annual Meeting of Transportation Research Board, January 22-26, 2006, Washington, D.C., CD-ROM.

Kořenská, M., Pazdera, L., Pospíšil, K. et. al. Detection of the Reinforcement Corrosion in Prestressed Concrete Girders. In 8th International Conference of the Slovenian Society for Non-destructive Testing: conference proceedings, Portorož (Slovinsko), 1.-3.10.2005. Portorož (Slovinsko) 2005, pp. 317 - 322. ISBN 961-90610-5-5.

Stryk J., Pospíšil K. Current possibilities of GPR usage in the field of transport infrastructure. In $4^{\text {th }}$ International Scientific Conference Challenges in Transport and Communications conference proceedings, Pardubice, 14.-15.9. 2006 [CD-ROM]. Pardubice : Univerzita Pardubice, 2006, 6 pages, ISBN 80-7194-880-2.

Stryk, J. Road Diagnostics - Ground Penetrating Radar Possibilities. In Fifth International Symposium Highway and Bridge Engineering 2007 : proceedings, Iaşi, România, 7. 12. 2007. Iaşi: Matei - Teiu Botez, 2007, pp. 18 -27, ISBN 978-973-8955-29-5.

Štulířová, J., Pospíšil, K. Observation of Bitumen Microstructure Changes using Scanning Electron Microscopy. Road Materials and Pavement Design, 2008, Vol. 9, No. 4, pp.745754. ISBN 1468-0629.

Utsi V., Utsi E.: Measurement of Reinforcement Bar Depths and Diameters in Concrete. In: $10^{\text {th }}$ International Conference on Ground Penetrating Radar, 21-24 June, 2004, Delft, pp. 659-662. 